\title{
PROCESSOS DE PRODUÇÃO DE VÍDEO-AULA
}

\author{
Greicy Kelli Spanhol \\ Programa de Pós-Graduação em Engenharia e Gestão do Conhecimento (PPEGC) \\ Universidade Federal de Santa Catarina (UFSC) \\ greicy@egc.ufsc.br
}

Fernando José Spanhol, Dr.

Laboratório de Educação a Distância (LED)

Universidade Federal de Santa Catarina (UFSC)

spanhol@led.ufsc.br

\section{Resumo}

Este artigo objetiva apresentar a melhoria no fluxo de processos de produção de vídeoaula do LED/dEGC/UFSC. Com o gerenciamento dos processos e estabelecimento de indicadores e medidas de desempenho foi possível acompanhar, avaliar e melhorar o desempenho dos mesmos. A metodologia empregada foi a abordagem qualitativa, a pesquisa descritiva, documental e aplicada e o estudo de caso. Foram identificados os problemas que ocorriam na gravação, edição, validação e publicação das vídeo-aulas. Para melhorar o desempenho do fluxo foram inseridos dois sub-processos e duas atividades que auxiliaram na diminuição de inconformidades e promoveram a melhoria dos produtos do laboratório.

Palavras-Chave: vídeo-aula, gestão de processos, produção

\section{PROCESSES FOR PRODUCTION OF VIDEO-CLASS}

\begin{abstract}
This paper aims to present the improvement in the flow of the production of video-class LED/dEGC/UFSC. With the management of processes and establishment of indicators and measures of performance was possible to monitor, evaluate and improve the performance of them. The methodology used was the qualitative approach, the descriptive, documentary and applied research and the case of study. We identified the problems that occurred in recording, editing, validation and publication of video-class. To improve the performance of the flow were inserted two sub processes and two activities that helped in reducing non-conformities and promoted the improvement of laboratory products.
\end{abstract}

Keywords: class-video, process management, production

\section{INTRODUÇÃO}

A educação a distância (EAD) é uma modalidade de ensino/aprendizagem "[...] onde as ações do professor e do aluno estão separadas no espaço e/ou no tempo" (SANTOS,1999, p. 2). Assim, "um sistema de educação a distância é formado por todos os processos componentes que operam quando ocorre o ensino e o aprendizado a 
distância. Ele inclui aprendizado, ensino, comunicação, criação e gerenciamento". (MOORE e KEARSLEY, 2007, p. 9).

Para promover o ensino/aprendizagem a EAD também utiliza diferentes tipos de mídias como: materiais impressos, rádio, telefone, televisão, videoconferência, e-mail, hipermídia e multimídias de computador, para proporcionar ao estudante maior interação com o conteúdo. Assim, os materiais didáticos em EAD são um importante aspecto para a transmissão do conteúdo, sendo que a sua produção envolve processos que seguem um fluxo bem definido, pois o foco está sempre na qualidade do material.

Entre os materiais didáticos, um dos mais utilizados pelo Laboratório de Educação a Distância (LED) do Departamento de Engenharia do Conhecimento (dEGC) da Universidade Federal de Santa Catarina (UFSC), é a vídeo-aula. Deste modo, este artigo tem por objetivo apresentar o fluxo de processos de produção de vídeo-aula do LED/dEGC/UFSC, que constantemente busca o aprimorando dos seus materiais para promover a disseminação do conhecimento com qualidade.

\section{METODOLOGIA}

Para realização deste artigo foi eleita a abordagem qualitativa, pois esta permite a "análise de microprocessos, através do estudo das ações sociais individuais ou grupais" (Martins, 2004, p.292).

Quanto aos tipos de pesquisa foram: a pesquisa descritiva, a aplicada e a documental, sendo a técnica utilizada o estudo de caso.

A pesquisa descritiva tem "como objetivo primordial a descrição das características de determinada população ou fenômeno ou, então, o estabelecimento de relações entre as variáveis" (Gil, 2009, p. 42). Este estudo é descritivo, pois buscou observar fenômenos, realizando uma descrição, classificação e interpretação dos mesmos.

Já, a pesquisa aplicada "objetiva gerar conhecimentos para aplicação prática e dirigida à solução de problemas específicos" (Souza et al. 2007, p. 38). Esta investigação é aplicada uma vez que buscou resolver problemas no fluxo de processos de produção de vídeo-aulas realizados no LED/dEGC/UFSC.

Conforme Gil (2009, p. 42) a pesquisa documental "vale-se de materiais que não receberam tratamento analítico". Sendo que para elaboração do artigo os dados coletados foram de fonte primária.

A técnica de pesquisa utilizada foi o estudo de caso, pois este é um estudo contínuo e aprofundado sobre um evento específico (Souza et al., 2007). E para tal foram observadas 80 vídeo-aulas no decorrer de 3 meses, acompanhando e avaliando detalhadamente todos os aspectos do fluxo de produção.

\section{VÍDEO-AULA}

A vídeo-aula é um recurso audiovisual produzido para atingir objetivos específicos da aprendizagem. Para Arroio e Giordan (2006, p.1) a vídeo-aula é uma "modalidade de exposição de conteúdos de forma sistematizada", sendo que

esta modalidade se mostra didaticamente eficaz quando desempenha uma função informativa exclusiva, na qual se almeja transmitir informações que precisam ser ouvidas ou visualizadas e que encontram no audiovisual o melhor meio de veiculação (Arroio e Giordan, 2006, p.1). 
As vídeo-aulas podem ser oferecidas em diferentes formatos de linguagem, entre eles: aula gravada em estúdio com cenografia customizada, em cenários reais ou locações vinculadas ao conteúdo do curso, documentários, entrevistas, debates, matérias pré-produzidas, etc. Para Sartori e Roesler (2005, p. 150)

os diversos formatos possíveis são decididos pela equipe de produção em função dos objetivos de aprendizagem que se deseja alcançar, da adequação entre o formato proposto e a natureza do conteúdo a ser abordado, bem como das condições para a produção, como orçamento e tempo disponível.

A equipe de produção é multidisciplinar e composta por roteiristas, cinegrafistas, profissionais da comunicação, pedagogos, psicólogos, entre outros, que além de garantir o funcionamento do SET de gravação, ainda dão o suporte ao professor, para planejar e estruturar o roteiro, bem como garantir uma efetividade nas questões técnicas e pedagógicas da produção audiovisual.

A preparação de uma vídeo-aula envolve um fluxo do processo que é bem definido, sendo que este fluxo deve ser constantemente atualizado, pois com a evolução das Tecnologias da Informação e Comunicação (TICs), principalmente dos equipamentos de áudio e vídeo é possível enriquecê-los, de maneira a potencializarem cada vez mais o processo de ensino/aprendizagem.

Para Dallacosta et al. (2004, p.3) as TICs "fazem parte do cotidiano da sociedade atual, modificando assim, as relações educacionais, bem como a relação com o saber. A multiplicidade de informações é uma realidade e os vídeos têm de ser considerados nesta perspectiva". Os autores ainda afirmam que

\footnotetext{
a vídeo-aula quando bem planejada, consegue fazer com que os alunos participem ativamente, muitas vezes procurando certo conteúdo que os professores tem dificuldade de encontrar devido às diversidades e acessibilidade de fontes de informações em nossa sociedade (Dallacosta et al., 2004, p.1).
}

Considerando o exposto por Dallacosta, a vídeo-aula é um recurso que impulsiona a disseminação do conhecimento, e para difundir o conhecimento com qualidade, o LED vem melhorando os seus processos de produção.

\section{PROCESSO DE PRODUÇÃO DE VÍDEO-AULA NO LED/dEGC/UFSC}

Vargas, Rocha e Freire (2007) afirmam que a produção de vídeos digitais voltados para a aprendizagem apontam para diversos benefícios educacionais, sendo estes: Desenvolvimento do pensamento crítico; Promoção da expressão e da comunicação; Favorecimento de uma visão interdisciplinar; Integração de diferentes capacidades e inteligências; e Valorização do trabalho em grupo.

Assim, os setores da educação devem melhorar seu desempenho, reavaliando valores para os parceiros, e estruturando suas operações de forma sistêmica e integrada, contando com pessoas potencializadas e trabalhando em equipe, a fim de melhorar continuamente tais processos organizacionais (Laurindo e Rotonardo, 2006).

Objetivando melhorar o processo de produção de vídeo, a equipe envolvida deve estar atenta ao fluxo deste, bem como a situação atual do processo e os desvios do que foi planejado.

Um processo "é qualquer atividade ou conjunto de atividades que toma um input, adiciona valor a ele e fornece um output a um cliente específico" (Gonçalves, 2000a, p.7). Os processos são compostos por sub-processos, atividades e tarefas. Os sub- 
processos são divisões do processo com objetivos específicos recebendo suas entradas e saídas para atender as especificações de cada processo. As atividades "são unidades de trabalho executadas dentro de um processo" (De Sordi, 2008, p. 59). E as tarefas "são um conjunto de atividades diferenciadas e conduzidas por metas seqüenciáveis" (Swales, 1990, p.76).

Destarte, um fluxo de processo de produção é composto por diversos subprocessos, atividades e tarefas. E para garantir a qualidade desses processos se faz necessário acompanhar e avaliar o desempenho dos mesmos. Para tal, busca-se eleger indicadores e medidas de desempenho. Os indicadores têm como função indicar as possíveis melhorias no processo produtivo, e as medidas de desempenho devem indicar os problemas que podem causar resultados indesejados (Nuitin, 2007).

Deste modo, para atingir um fluxo de processos eficiente e eficaz busca-se observar: os níveis de produtividade; a qualidade dos produtos; a programação da produção; os custos e as despesas; sendo que "para isso, a avaliação do desempenho, do processo de produção, requer indicadores não só quantitativos, mas também qualitativos" (Nuitin, 2007, p. 49).

Buscando assegurar um fluxo de processo que garanta a qualidade do conteúdo a ser disseminado, o LED constantemente avalia, acompanha, gerencia, atualiza e melhora a sua forma de produzir materiais audiovisuais.

\subsection{Fases do Processo de Produção de Vídeo-aula}

No LED as vídeo-aulas são aulas gravadas em estúdio devidamente preparado com cenografia e iluminação específica. Os professores, nestes estúdios, dispõem de recursos técnicos como: câmera de documentos, captura de tela do computador, microfone unidirecional com cancelador de eco, câmera robô e teleprompter. O Fluxo de Processos de Produção de uma vídeo-aula é composto por 3 fases, sendo estas: préprodução, produção e pós-produção.

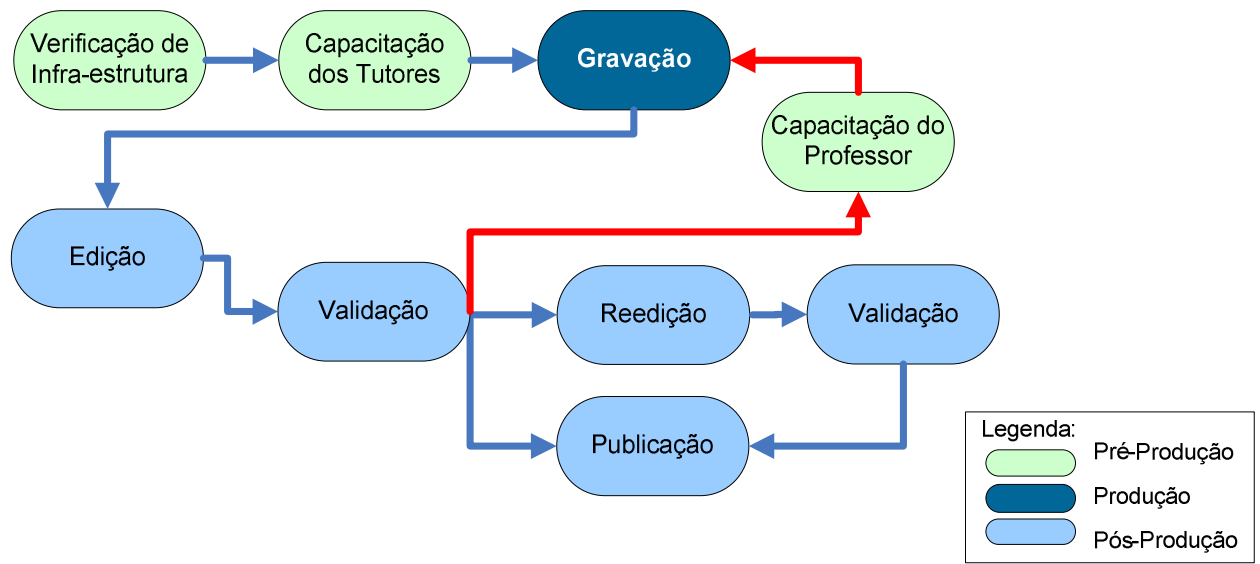

Figura 1: Fluxo do Processo de Produção de Vídeo-aula (LED)

A fase de pré-produção "consiste na preparação, planejamento e projeto do vídeo a ser produzido. Essa etapa abrange todas as demais atividades que serão realizadas, desde a concepção da idéia inicial até a filmagem" (Vargas et al., 2007, p. 3).

No LED esta fase inicia com o brainstorming sobre o tipo de aula, seguindo-se da capacitação dos tutores que acompanham os professores durante a gravação. Em um 
primeiro momento optou-se apenas pela capacitação dos tutores por serem estes os responsáveis pelo roteiro da aula, bem como devido ao fato dos professores terem menor disponibilidade de tempo. Como os tutores construíam o roteiro juntamente ao professor, entendia-se que os mesmos passariam todas as informações necessárias à gravação. Costa (1978 p. 43 apud Cinelli, 2003, p. 37) afirma que

\begin{abstract}
a utilização de recursos audiovisuais deve ser planificada com antecedência e nunca improvisada. O professor deve caracterizar e delimitar bem aquilo que dentro do razoável, pretende que seus alunos aprendam. Escolhe, então os recursos audiovisuais mais apropriados ao caso e dos quais possa dispor. Estuda esses recursos, a forma e o momento de sua aplicação.
\end{abstract}

Na capacitação dos tutores são explicadas questões como: formatação da apresentação, roupagem adequada ao ambiente, linguagem a ser utilizada, etc. Após esta etapa, o próximo passo é a verificação e preparação da infra-estrutura para gravação (são testados todos os equipamentos do estúdio e preparado o cenário específico).

A fase de produção "é a etapa que são feitas as filmagens das cenas que compõem o vídeo" (Vargas et al., 2007, p. 3). Deste modo, esta fase é composta pela gravação da vídeo-aula com o acompanhamento do tutor e de um técnico que auxiliam o professor na utilização dos recursos disponíveis no estúdio. O apoio é importante, pois "para que o professor possa aproveitar o máximo o conteúdo do vídeo como recurso auxiliar do ensino, é necessário que conheça aquilo que este recurso didático pode oferecer" (Cinelli, 2003, P.37).

A equipe de acompanhamento também é responsável pelos seguintes aspectos na gravação: enquadramento do plano visual (são pré-definidos 5 planos e alterados conforme a necessidade), linguagem, tempo de gravação, apresentação visual do professor, som, luz e acompanhamento do roteiro pré-produzido.

A fase de pós-produção "recobre todas as atividades até então realizadas para a finalização do vídeo quando se faz a edição e a organização das tomadas gravadas para a composição das cenas do vídeo como um todo" (Vargas et al., 2007, p. 3).

Nesta fase é executada a edição e a posteriori a validação, que tem o objetivo de controle de qualidade, observando a coerência do conteúdo e a adequação de linguagem (Spanhol, 1999). Durante a edição são cortadas partes que não irão para a versão final da aula, em média o arquivo bruto possui 50 minutos de gravação e o produto final apenas 30 minutos. Deve-se ressaltar que este tempo refere-se ao projeto eleito para esse estudo de caso, sendo este um curso da UFSC, ofertado pelo ao sistema Universidade Aberta do Brasil (UAB) que está em execução e terá duração de 4,5 anos, sendo realizadas cerca de 35 vídeo-aulas por mês.

Além disso, nesta etapa ocorre à criação de grafismos para o vídeo com a inserção de imagens, gerador de caracteres, músicas e animações em consonância com o conteúdo e a proposta pedagógica do curso. A "utilização de vídeos, sendo estes significativos e integrados aos temas trabalhados levando em conta uma concepção de currículo integrado, tornará a aprendizagem mais significativa" (Dallacosta et al., 2004, p.3).

Depois de inserido o material gráfico, o arquivo é disponibilizado no ambiente de rede, validado pela equipe pedagógica e publicado. Não sendo aprovado em sua primeira versão, a vídeo-aula é reeditada, ou até mesmo regravada. No caso de reeditada ocorre uma nova validação e aprovada segue para a publicação. Quando ocorre a necessidade de regravação é preciso capacitar o professor, regravar, editar, validar e posteriormente publicar. 


\subsection{Análise do Processo de Produção de Vídeo-aula}

Embora o fluxo dos processos fosse detalhado, observou-se que havia muitas necessidades de reedição das vídeo-aulas, e em alguns casos até mesmo de regravação. Objetivando identificar as falhas no processo e melhorar a qualidade da vídeo-aula, buscou-se observar 40 vídeos já gravados, assim, foram estabelecidas algumas medidas de desempenho, sendo os seguintes indicadores nos sub-processos:

\begin{tabular}{|l|l|}
\hline SUB-PROCESSO & \multicolumn{1}{|c|}{ MIDIDAS DE DESEMPENHO } \\
\hline Gravação & $\begin{array}{l}\text { Qualidade dos slides (padrão), luz, tempo de gravação vestimenta apropriada, } \\
\text { interrupções e reinícios da gravação. }\end{array}$ \\
\hline Edição & $\begin{array}{l}\text { Tempo de edição e quantidade de falhas encontradas; } \\
\text { Problemas de edição e verificação da qualidade de som (alcance do microfone, } \\
\text { volume da voz, linguagem utilizada) e imagem (vestimenta, luz e slides). }\end{array}$ \\
\hline Validação & $\begin{array}{l}\text { Número de aulas não aprovadas na primeira versão, qualidade dos slides } \\
\text { (padrão), luz, tempo de gravação e vestimenta apropriada. }\end{array}$ \\
\hline Regravação & Tempo de reedição e quantidade de falhas apontadas pela validação. \\
\hline Reedição & Publicação, produto pronto e entregue ao cliente. \\
\hline Nível de \\
Produtividade
\end{tabular}

\section{Quadro 1: Medidas de Desempenho}

Após a análise, os indicadores de inconformidade encontrados foram: Vestimenta inadequada dos professores; Slides não padronizados, com cores, tamanho de fontes e formatos inadequados; Aulas excedendo o tempo; Pouco uso dos recursos, Ruídos freqüentes devido o microfone ter sua base na mesa; Professores inseguros pela não familiaridade com o ambiente e que acabavam por reiniciar as gravações diversas vezes.

Das 40 aulas, 5 tiveram que ser regravadas e 17 reeditadas, sendo as razões encontradas em diferentes etapas do processo. Abaixo os erros ocorridos em cada subprocesso, sendo que devido a estas inconformidades encontradas as vídeo-aulas não puderam ser aprovadas em seu formato final para publicação.

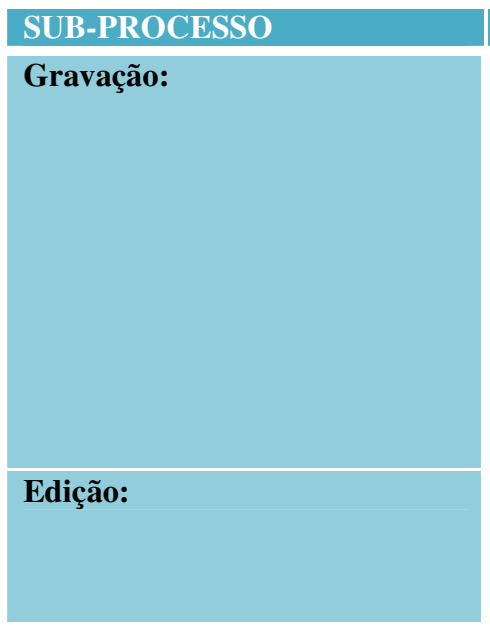

\section{INCONFORMIIDADES}

$\checkmark$ Qualidade dos slides (padrão);

$\checkmark$ Ruídos frequientes devido o microfone ter sua base na mesa;

$\checkmark$ Qualidade do som;

$\checkmark$ Tempo de gravação (10 aulas passaram de 1 hora e 4 passaram de 1 h e $20 \mathrm{~min}$ );

$\checkmark$ Vestimenta inadequada;

$\checkmark$ Não seguir o roteiro;

$\checkmark$ Professores inseguros pela não familiaridade com o ambiente e que acabavam por interromper e reiniciar as gravações diversas vezes;

$\checkmark$ Não utilização dos recursos adequados.

$\checkmark$ Dificuldades de edição por não seguir o roteiro estabelecido;

$\checkmark$ Falhas na edição devido ao tempo da mesma, que levou cerca de 3 horas cada aula tendo como principal motivo os professores reiniciarem as gravações diversas vezes. 


\begin{tabular}{|l|ll}
\hline Regravação: & $\checkmark$ & Não foram encontradas falhas que inviabilizassem o formato \\
& final da vídeo-aula. \\
\hline Na Reedição: & $\checkmark$ & Não foram encontradas falhas que inviabilizassem o formato \\
& final da vídeo-aula. \\
\hline Nível de Produtividade: & $\checkmark$ & Em média 12 horas para gravação e edição em cada vídeo-aula. \\
\hline Custos: & $\checkmark$ & Necessidade de $55 \%$ de retrabalho em diferentes pontos, \\
& impactando em um custo maior número de horas de mão-de- \\
& obra.
\end{tabular}

Quadro 2: Inconformidades ocorridas no Processo de Produção de Vídeo-Aula LED

Com a análise destes dados, verificou-se que $80 \%$ dos erros apresentados acontecem na gravação, e os outros $20 \%$ na edição. Assim, definiu-se como atividade crítica a gravação, pois este é o momento onde todas as variáveis já devem estar organizadas, ou seja, os aspectos técnicos (infra-estrutura técnica, cenografia, professores com vestimenta adequada para televisão e capacitado para gravação, apresentações gráficas revisadas e adequadas ao formato televisivo).

Um ponto importante que ficou evidenciado é que não era o suficiente apenas capacitar o tutor, se fazia necessário também capacitar e preparar o professor, bem como disponibilizar um profissional de vídeo que acompanhasse a aula durante todo o processo de gravação e edição.

\subsection{Mudanças no Processo de Produção de Vídeo-aula}

O fluxo apresentado na figura 1 já não supria as necessidades da produção, pois $55 \%$ das vídeo-aulas precisaram de algum tipo de ajuste. Objetivando minimizar o custo operacional e as falhas do processo, foram inseridos 2 novos sub-processos: a capacitação dos professores e a validação da imagem antes de gravar. Houve a necessidade de inserir 2 atividades no fluxo de produção: o acompanhamento de um diretor de vídeo durante o processo de gravação e de edição conforme figura 2.

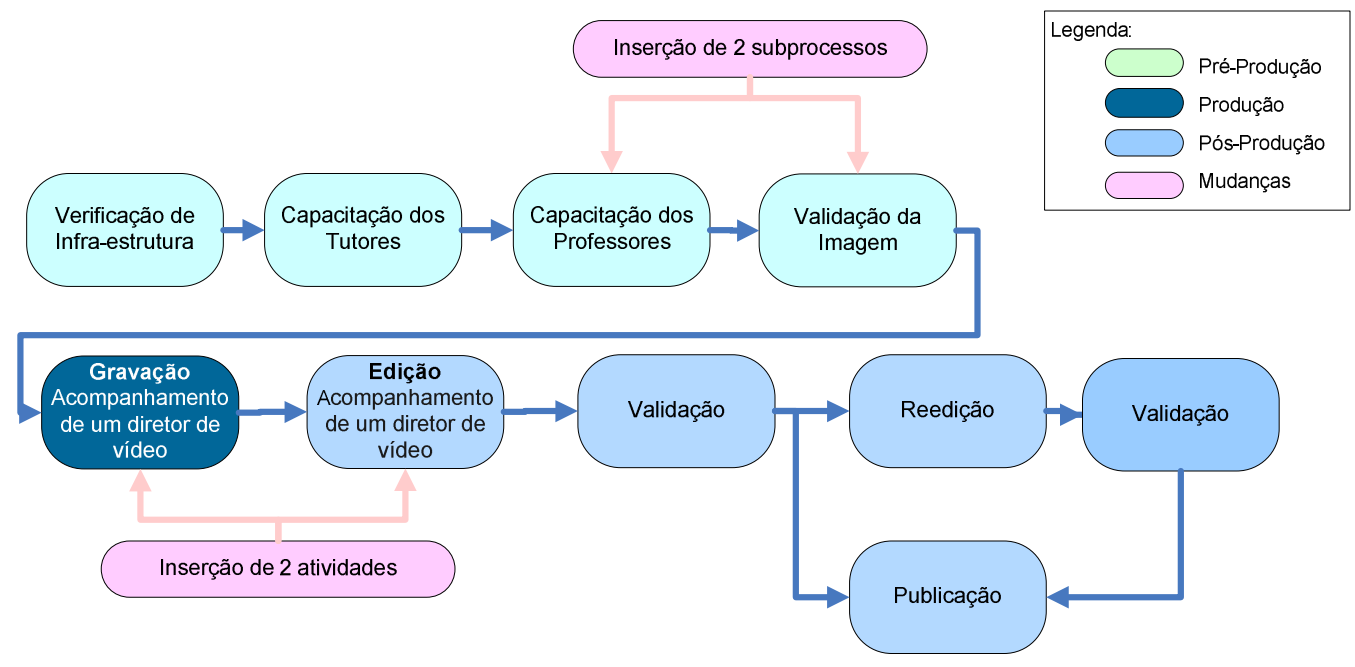

Figura 2: Novo Fluxo de Processos de Produção de Vídeo-aula (LED)

A partir da inserção dos sub-processos e das atividades foram analisadas mais 40 vídeo-aulas, considerando as mesmas medidas de desempenho. Apenas 6 aulas precisaram ser reeditadas e não houve nenhuma regravação, reduzindo assim o índice de 
necessidades de ajuste de 55\% para apenas $15 \%$. A tabela a seguir apresenta os resultados obtidos.

\begin{tabular}{|c|c|}
\hline SUB-PROCESSO & RESULTADOS \\
\hline Gravação & $\begin{array}{l}\checkmark \text { Menor tempo de gravação devido aos professores seguirem o roteiro } \\
\text { (100\% das aulas duraram aprox. } 50 \text { minutos); } \\
\checkmark \text { Vestimenta adequada (100\% dos professores); } \\
\checkmark \text { Redução dos ruídos do microfone (foram colocadas espumas abaixo do } \\
\text { microfone e assim, não havia barulho do impacto com a mesa); } \\
\checkmark \text { Utilização adequada dos recursos técnicos do estúdio (100\% dos } \\
\text { professores sabiam como utilizar os equipamentos); } \\
\checkmark \text { Redução de cerca de 80\% das interrupções das gravações pelos } \\
\text { professores; } \\
\checkmark \text { Maior qualidade de apresentações (100\% estavam padronizadas). }\end{array}$ \\
\hline Edição & $\begin{array}{l}\checkmark \text { Poucas dificuldades de edição, pois os professores seguiam o roteiro } \\
\text { estabelecido; } \\
\checkmark \quad \text { Redução de até } 3 \text { horas na edição. }\end{array}$ \\
\hline Regravação & $\checkmark$ Não foi preciso efetuar nenhuma regravação. \\
\hline Reedição & $\begin{array}{l}\checkmark \text { Apenas } 6 \text { aulas precisaram ser reeditadas com necessidade de poucos } \\
\text { acertos. }\end{array}$ \\
\hline $\begin{array}{l}\text { Nível de } \\
\text { Produtividade: }\end{array}$ & $\begin{array}{l}\checkmark \text { Em média } 8 \text { horas para cada aula. Diminuição em média de } 4 \text { horas para } \\
\text { produção de cada vídeo. }\end{array}$ \\
\hline Custos: & $\begin{array}{l}\checkmark \text { Eliminação de } 40 \% \text { do retrabalho, impactando na redução dos custos } \\
\text { devido ao menor número de horas de mão-de-obra empregada. }\end{array}$ \\
\hline \multicolumn{2}{|c|}{ Quadro 3: Resultados da análise do Processo atualizado de Produção de Vídeo-Aula LED } \\
\hline $\begin{array}{l}\text { Com o acom } \\
\text { belecimento d } \\
\text { orodução de víc } \\
\text { ção, validação } \\
\text { oratório. }\end{array}$ & $\begin{array}{l}\text { lamento e identificação dos gargalos no processo e com o } \\
\text { didas de desempenho foi possível inserir modificações no fluxo } \\
\text { ula, impactando na diminuição dos problemas de gravação, } \\
\text { licação, proporcionando a melhoria contínua dos produtos do }\end{array}$ \\
\hline
\end{tabular}

\section{CONSIDERAÇÕES FINAIS}

As possibilidades de disseminação do conhecimento aumentaram de forma exponencial a partir da incorporação das Tecnologias de Informação e Comunicação na Educação. A introdução do vídeo previamente gravado e com linguagem audiovisual adequada permitiram não só mostrar a imagem do professor, como também exemplificar conteúdos com riqueza de detalhes e informações promovendo assim, uma maior compreensão do aluno sobre os conteúdos das aulas.

Porém, não se deve apenas introduzir tecnologias, ou mesmo apresentar vídeos nas aulas, o uso desses precisa ser contextualizado e planejado para atender as necessidades pedagógicas para difusão do conteúdo. Ao construir um vídeo com objetivos pedagógicos, se faz necessário conhecer os processos de produção para que seja possível efetivar todas as vantagens que este recurso audiovisual oferece ao ensino/aprendizagem.

Deste modo, com a compreensão das técnicas de produção e com o acompanhamento do fluxo do processo, é possível inferir modificações e melhorias para garantir a eficiência e eficácia dos produtos audiovisuais, promovendo a melhoria continua das vídeo-aulas, buscando a excelência na efetivação da disseminação dos conteúdos necessários aos aprendizes para a formação profissional de todo o País. 


\section{REFERÊNCIAS BIBLIOGRÁFICAS}

ARROIO, A.; GIORDAN, M. O Vídeo Educativo: Aspectos da Organização do Ensino. In: Educação em Química e Multimídia, n 24, Nov-2006. Disponível em: $<$ http://qnesc.sbq.org.br/online/qnesc24/eqm1.pdf>Acesso em: 04 Maio 2009.

CINELLI, Nair Pereira Figueiredo. A influência do vídeo no processo de aprendizagem. Florianópolis: Programa de Pós-Graduação em Engenharia de Produção-UFSC, 2003.

73 f. Dissertação de Mestrado.

DALLACOSTA, A.; TAROUCO, L. M. R.; DUTRA, R. L. de S. A Utilização da Indexação de Vídeos com MPEG-7 e sua Aplicação na Educação. RENOTE. Revista Novas Tecnologias na Educação, v. 2, p. 1-10, 2004. Disponível em: $<$ http://www.cinted.ufrgs.br/renote/mar2004/artigos/35-autilizacao.pdf> Acesso em: 04 Maio 2009.

DE SORDI, José Osvaldo. Gestão por Processos: uma abordagem da moderna administração. 2 ${ }^{\text {a }}$. Ed. São Paulo: Saraiva, 2008.

GIL, Antonio Carlos. Como elaborar projetos de pesquisa. 4. ed. São Paulo: Atlas, 2009. 176 p.

GONÇALVEZ, José Ernesto Lima. As empresas são grandes coleções de processos. In: REA - Revista de Administração de Empresa. São Paulo: vol. 40, N.1, p. 6-19, JaneiroMarço 2000.

LAURINDO, José Fernando Barbin e ROTONARDO, Roberto Gilioli. Gestão

Integrada de Processos e da Tecnologia da Informação. São Paulo: Editora Atlas S.A, 2006.

MARTINS, H. H. T. de Souza. Metodologia qualitativa de pesquisa. In: Educação e Pesquisa, São Paulo, v. 30, n.2, p. 289-300, maio/ago, 2004

MOORE, M; KEARSLEY, G. Educação a Distância: uma visão integrada. Trad. Roberto Galman. São Paulo: Thomson Learning, 2007.

NUITIN, Adriano Antonio. O desenvolvimento de indicadores de desempenho e da qualidade para o processo de produção: estudo de casos do processo de produção de café. Ribeirão Preto: Faculdade de Economia, Administração e Contabilidade-USP, 2007. Dissertação de Mestrado.

SANTOS, E. T. Conceitos, tecnologias, cosntatações, presunções e recomendações. E. T. Santos, M. Rodrigues. São Paulo:EPUSP, 1999.

SOUZA, A. C. de; FIALHO, F. A. P.; OTANI, Nilo. TCC: Métodos e Técnicas.

Florianópolis: Visual Books, 2007.

SPANHOL, F. J. Estruturas tecnológica e ambiental de sitsemas de videoconferência na educação a distância: estudo de caso do Laboratório de Ensino a distância da UFSC.

Florianópolis: Programa de Pós-graduação em Engenharia de Produção-Universidade Federal de Santa Catarina, 1999. Dissertação de Mestrado.

SARTORI, Ademilde; ROESLER, Jucimara. Educação Superior a Distância: gestão a aprendizagem e da produção de materiais didáticos impressos e on-line. Tubarão: Ed. Unisul, 2005.

SWALES, J. M. Genre analysis: English in academic and research settings. New York: Cambridge University Press, 1990.

VARGAS, Ariel; ROCHA, Heloísa Vieira da; FREIRE, Fernanda Maria Pereira. Promídia: produção de vídeos digitais no contexto educacional. Novas Tecnologias $\mathrm{Na}$ Educação, Porto Alegre, v. 5, n. 2, dez. 2007. Semestral. Disponível em:

<http://www.cinted.ufrgs.br/ciclo10/artigos/1bAriel.pdf>. Acesso em: 30 abr. 2009. 